\title{
Adventitious Shoot Organogenesis and Plant Regeneration from Cotyledons of Tetraploid Watermelon
}

\author{
Michael E. Compton ${ }^{1}$ and D.J. Gray ${ }^{2}$ \\ University of Florida, Institute of Food and Agricultural Sciences, Central \\ Florida Research and Education Center, 5336 University Avenue, Leesburg, \\ FL 34748
}

Additional index words. Citrullus lanatus, cucurbits, tissue culture

\begin{abstract}
Cotyledon explants of four watermelon [Citrullus lanatus (Thunb.) Mataum. \& Nakai] breeding lines (F92U8, SP90-1, SP90-2, and SP90-4) were prepared from mature seed or from 2-, 4-, 6-, 8-, or 10-day-old seedlings. Explants were incubated on shoot regeneration medium for 8 weeks followed by 4 weeks on shoot elongation medium. The four genotypes differed in their ability to produce shoots at each explant age. The highest frequency with which F92U8 $(66 \%)$ and SP90-2 (60\%) explants produced shoots was for 2-day-old seedlings. Fewer explants formed shoots when established from mature seed or seedlings older than 2 days. In contrast, the percentage of SP90-4 explants that produced shoots was highest when cotyledons were obtained from 4-day-old seedlings $(40 \%)$, but the response was less than the optimum for F92U8 and SP90-2. SP90-1 cotyledon explants exhibited the poorest response of the four breeding lines ( $<11 \%$ produced shoots), with little difference in response among the explant ages tested. The number of shoots per responding explant also depended on the age of the explant source. Explants from 2- to 4-day-old seedlings produced the most shoots. Fewer shoots formed on cotyledons from mature seed or seedlings older than 4 days.
\end{abstract}

Adventitious shoot regeneration has been reported from cotyledons of tetraploid watermelon; however, the percentage of explants that produced shoots was low $(<50 \%$; Compton and Gray, 1993) or undocumented (Anghel and Rosu, 1985). High frequency shoot regeneration $(\geq 75 \%)$ has been obtained for diploid watermelon by using cotyledon explants from 5-day-old in vitro-germinated seedlings (Compton and Gray, 1993; Dong and Jia, 1991). But, applying the methods used for adventitious shoot organogenesis of diploid watermelon to tetraploid genotypes has resulted in poor shoot-regeneration rates. Compton and Gray (1993) demonstrated that the most important factors for adventitious

Received for publication 26 Apr. 1993. Accepted for publication 28 Sept. 1993. This is Florida Agricultural Experiment Station journal series no. R-03121. Seeds were provided by Gary W. Elmstrom, Central Florida Research and Education Center, Institute of Food and Agricultural Sciences, Univ. of Florida, Leesburg. This work was supported by a grant from the State of Florida High Technology and Industry Council Applied Research Grants Program. Mention of trademark, proprietary product, or vendor does not constitute a guarantee or warranty of the product and does not imply its approvat to the exclusion of other products or vendors that also may be suitable. The cost of publishing this paper was defrayed in part by the payment of page charges. Under postal regulations, this paper therefore must be hereby marked advertisement solely to indicate this fact.

'Postdoctoral Research Associate. To whom reprint requests should be addressed

${ }^{2}$ Professor shoot regeneration in diploid watermelon were the plant genotype and seedling age at the time of explant preparation. Hence, the objective of this study was to determine the optimal seedling age for adventitious shoot production from cotyledons of four tetraploid watermelon breeding lines.

\section{Materials and Methods}

Experimental protocol. Watermelon seeds were surface-disinfested for $30 \mathrm{~min}$ in $2.5 \%$ $\mathrm{NaClO}$ plus two drops Triton X-100 (Poly sciences, Warrington, $\mathrm{Pa}$.) per $100 \mathrm{ml}$, rinsed five times with sterile distilled water, and soaked overnight (maximum $15 \mathrm{~h}$ ) in sterile distilled water in darkness. Embryos were extracted by removing the seedcoat followed by surface disinfestation in $1.25 \% \mathrm{NaClO}$ plus two drops Triton X- 100 per $100 \mathrm{ml}$ for $20 \mathrm{~min}$ and six sterile distilled water rinses. Embryos (nine per vessel) of four tetraploid breeding lines (F92U8, SP90-1, SP90-2, and SP90-4) were germinated in Magenta $\mathrm{GA}_{7}$ vessels (Magenta Corp., Chicago) containing $50 \mathrm{ml}$ of germination medium [MS salts (Murashige and Skoog, 1962) plus (per liter) $20 \mathrm{~g}$ sucrose, $100 \mathrm{mg}$ myo-inositol, $2 \mathrm{mg}$ glycine, $0.5 \mathrm{mg}$ pyndoxine $\mathrm{HCl}, 0.5 \mathrm{mg}$ nicotinic acid, $0.1 \mathrm{mg}$ thiamine $\mathrm{HC1}$, and $7 \mathrm{~g}$ TC agar (JRH Biosciences, Lenexa, Kan.)]. The medium $\mathrm{pH}$ was adjusted to 5.7 with $1 \mathrm{~N} \mathrm{KOH}$ or $1 \mathrm{~N} \mathrm{HCl}$ before adding agar and autoclaving.

Cotyledons were excised from mature seed or from 2-,4-,6-, 8-, or 10-day-old seedlings. Explants were obtained by making a cut across the cotyledon $\approx 1$ to $2 \mathrm{~mm}$ above the point of attachment to the stem. The margins (1 mm) were removed and the cotyledons bisected crosswise. The apical portion was discarded, and the cotyledon base was cut in half longitudinally, resulting in a final explant size of $3 \times$ $5 \mathrm{~mm}$. Explants were cultured abaxial side down in $100 \times 15-\mathrm{mm}$ petri plates that contained $25 \mathrm{ml}$ of shoot regeneration medium [MS, as above, but with $30 \mathrm{~g}$ sucrose/liter and 10 рим N-(phenylmethyl)- 1H-purin-6-amine (BA) (Sigma Chemical, St. Louis) (Compton and Gray, 1993)]. Explants were subculture to fresh medium of the same composition at 4 weeks. After 8 weeks, explants with shoots were transferred to $100 \times 25$-mm petri plates that contained $30 \mathrm{ml}$ of shoot elongation medium [MS, as above, but with $20 \mathrm{~g}$ sucrose/ liter and no BA (Compton and Gray, 1993)]. There were five plates per treatment with nine explants each. Cultures were maintained under a 16 -h photoperiod (30 to 50 $\mu \mathrm{mol} \cdot \mathrm{m}^{-2} \cdot \mathrm{s}^{-1}$ from cool-white fluorescent lamps) at $25 \mathrm{C}$.

Design and data analysis. Treatments were arranged in a split-plot design with explant ages as main plots and genotypes as subplots. Because main plots were assigned at random (not blocked), the nested term replicate within explant age was used as the main-plot error (Lentner and Bishop, 1986). Genotype was assigned at random within whole plots, and the nested term genotype $x$ replicate within explant age was used as the subplot error. Data recorded at 12 weeks included the number of explants with shoots and the number of shoots per explant. The experiment was conducted twice. Statistical analysis was conducted using the GLM procedure of the Statistical Analysis System (SAS Inst., 1988). Data sets that contained a large number of zeros were transformed using the square root transformation [(y + 0.5) 1/2; Zar, 1984] before GLM analysis. Data on percent success were analyzed using the Catmod procedure (SAS Inst., 1988). Regression analysis was used to determine the effect of explant age on shoot regeneration for each genotype and the best model chosen using lack-of-fit (LOF) analysis (Kleinbaum and Kupper, 1978).

Rooting and acclimatization of regenerated plants. After 4 weeks on shoot elongation medium, shoots longer than $5 \mathrm{~mm}$ were excised and transferred to Magenta GA, vessels that contained $50 \mathrm{ml}$ of rooting medium [MS, as above, but with $20 \mathrm{~g}$ sucrose/liter and $1 \mu \mathrm{m}$ $1 \mathrm{H}$-indole-3-butyric acid (IBA) (Sigma Chemical, St. Louis)] for 3 weeks. Plants were transplanted to cell packs $(4.0 \times 5.5 \mathrm{~cm}$ with 72 cells/flat) filled with (by volume) 1 ProMix BX (Premier Brands, New Rochelle, N.Y.): 2 coarse vermiculite, covered with a clear plastic lid, and grown under the same conditions as the tissue cultures. When signs of new shoot growth were evident $(\approx 2$ weeks), the plants were acclimatized to ambient humidity levels by gradually removing the lid over 3 days. Plants were misted manually three to four times. daily with distilled water during this period to avoid desiccation. Acclimatized plants were moved to the greenhouse 2 weeks later and incubated under natural light and photoperiod. 


\section{Propagation \& Tissue Culture}

\section{Results and Discussion}

The tetraploid genotype tested and the seedling age at the time of explant preparation interacted significantly for the percentage of explants that produced shoots (Table 1). Regression and LOF analyses revealed that the response curve for each genotype differed. The response curve for F92U8 (Fig. 1A) and SP90-2 (Fig. 1B) fit the cubic model, but the regression equation differed for each. Thus, while both genotypes displayed the same basic trend, the slope of the lines differed. The regression line for the percentage of F92U8 explants that formed shoots indicated that the most responsive explants were cotyledons from 2-day-old seedlings (Fig. 1A). A 2.5-fold increase in the percentage of explants with shoots was observed between cotyledons from mature seed (0 days) and 2-day-old seedlings. The percentage of explants with shoots declined about six fold when cotyledons were obtained from 8-day-old seedlings. Regression analysis indicated that the decline occurred in two, parts: a small drop in response among cotyledons for the 2-day interval between 2-to 4-day-old seedlings (61\% to $54 \%)$ and a sharp decline between 4- and 8-day-old seedlings (54\% to $3 \%$ ). Cotyledons from 8 and 10-day-old seedlings responded similarly. Regression and LOF analyses indicated that the most responsive SP90-2 explants were cotyledons from 2-day-old seedlings (Fig. 1B). However, the slope of the regression line differed from that of F92U8. The increase in response indicated by the regression line was less dramatic between cotyledons from mature seed (0 days) and 2-day-old SP90-2 seedlings than for similar F92U8 explants (34\% to $43 \%$ and $24 \%$ to $61 \%$, respectively). A simple linear decline in response occurred during the 6-day interval for cotyledons obtained from 2to 8-day-old SP90-2 seedlings; in contrast, there were two separate linear slopes for similar F92U8 explants. Cotyledons from 8- and 10-day-old seedlings responded similarly. For SP90-4, the most responsive explants were cotyledons from 4-day-old seedlings (Fig. 1C). Regression and LOF analyses revealed that the quadratic model best fit the data, indicating that the response began low $(\approx 21 \%)$ for cotyledons from mature seed ( 0 days), peaked at $31 \%$ for cotyledons from 4 -day-old seedlings, and declined gradually to $4.7 \%$ for cotyledons

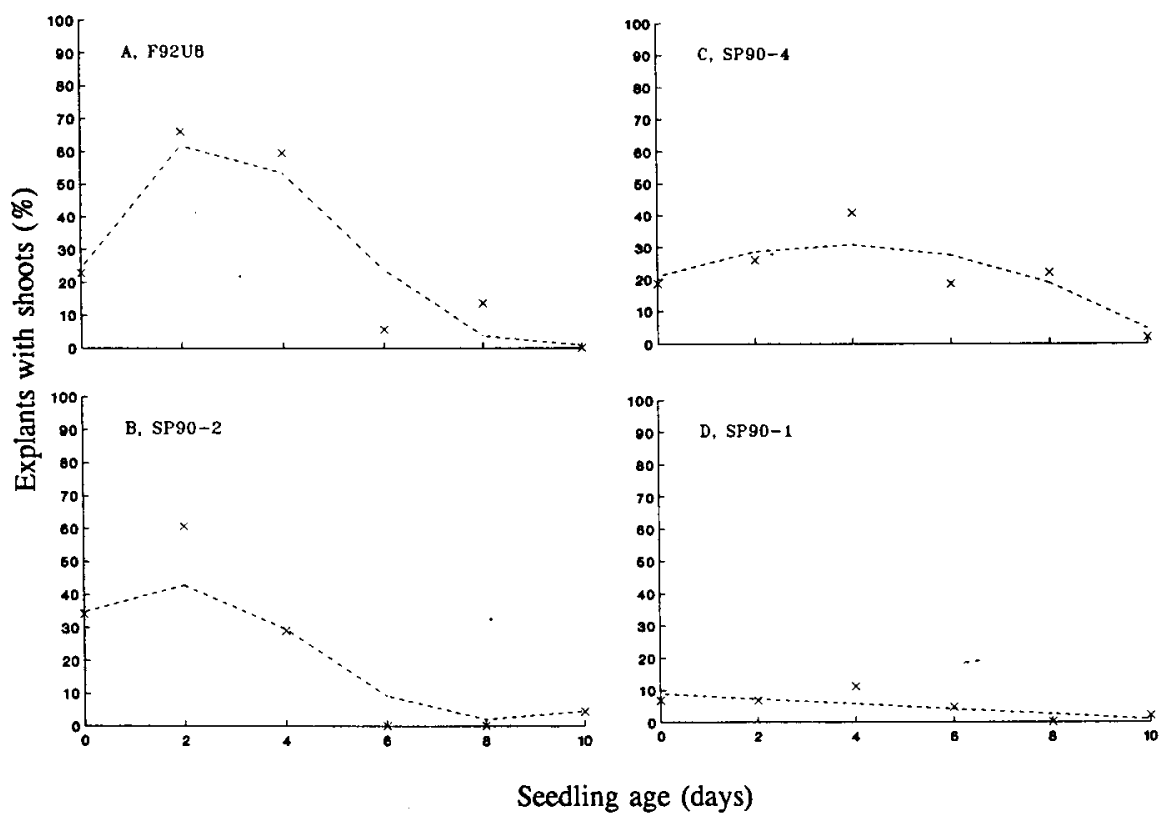

Fig. 1. Effect of seedling age on the percentage of cotyledon explants from seedlings of four tetraploid watermelon breeding lines (F92U8, SP90-2, SP90-4, and SP90-1) to form adventitious shoots. Explants were cotyledons from mature seed $(0)$ or 2-,4 -,6-, 8-, or 10-day-old in vitro-germinated seedlings. For protocols, see text. The number of explants per treatment ranged from 54 to 90 . Dotted lines represent the predicted regression line for each genotype $\left[\mathrm{Y}=24.16+34.57 \mathrm{x}-8.89 \mathrm{x}^{2}+0.52 \mathrm{x}^{3}(\mathrm{~F} 92 \mathrm{U} 8) ; \mathrm{Y}=34.65\right.$ $+11.89 \mathrm{x}-4.49 \mathrm{x}^{2}+0.3 \mathrm{x}^{3}(\mathrm{SP} 90-2) ; \mathrm{Y}=20.86+5.23 \mathrm{x}-0.685 \mathrm{x}^{2}(\mathrm{SP} 90-4) ; \mathrm{Y}=8.9-0.78 \mathrm{x}(\mathrm{SP} 90-1)$

from 10-day-old seedlings (Fig. 1C). Adventitious shoot organogenesis was generally lower for SP90-1 than for the other genotypes (Fig. 1D), failing to exceed $11 \%$ in the best treatment (explants from 4-day-old seedlings). The linear regression model best fit the response data for SP90-1, indicating that the ability of explants to produce shoots declined with time as cotyledons from mature seed ( 0 days) to 10-day-old seedlings were used (Fig. 1D).

The number of shoots per responding explant was significantly influenced by the age of the explant source (Table 1). Regression and LOF analyses revealed that the cubic model best described the data (Fig. 2). The number of shoots per responding explant increased linearly from 1.8 to 2.8 for cotyledons from mature seed to 2-day-old seedlings, respectively, then was similar for explants from 2- and 4-day-old seedlings, and declined when explants were obtained from 6- and 8-day-old seedlings. The number of shoots per respond-

Table 1. Analysis of variance summary table for the percentage of explants that produced shoots and the number of shoots per responding explant.

\begin{tabular}{|c|c|c|c|c|c|c|c|}
\hline \multirow[b]{2}{*}{ Source of variation } & \multirow[b]{2}{*}{ df } & \multicolumn{3}{|c|}{ Explants with shoots (\%) } & \multicolumn{3}{|c|}{$\begin{array}{c}\text { No. shoots/ } \\
\text { responding explant }\end{array}$} \\
\hline & & $\mathrm{MS}^{\mathrm{z}}$ & & & $\overline{\mathrm{MS}}$ & & \\
\hline Explant age & 5 & 1.04 & 8.33 & $* * *$ & 3.23 & 9.71 & $* * *$ \\
\hline Main-plot error ${ }^{y}$ & 24 & 0.12 & --- & & 0.33 & --- & \\
\hline Genotype & 3 & 0.68 & 9.89 & $* * *$ & 0.67 & 1.22 & NS \\
\hline Age $\times$ genotype & 15 & 0.23 & 3.33 & *** & 0.66 & 1.22 & NS \\
\hline Subplot error ${ }^{x}$ & 72 & 0.07 & --- & & 0.54 & --- & \\
\hline
\end{tabular}

${ }^{2}$ Mean square.

'Obtained from the nested term for a split-plot design where the main-plot factor is not blocked (replicate within explant age).

Obtained from the nested term for a split-plot design where the subplot factor is randomized within main plots (genotype $\times$ replicate within explant age).

***, ${ }^{\mathrm{Ns}}$ Significant at $P \leq 0.001$ or nonsignificant, respectively. ing explant was similar for cotyledons from 8 and 10-day-old seedlings. The number of shoots per responding explant was not affected by the explant genotype (Table 1).

The percentages of shoots that produced roots and plants that survived acclimatization to ambient environmental conditions were high (90\% and $75 \%$, respectively). The ability of shoots to root or plants to survive acclimatization was independent of plant genotype and seedling age.

This study demonstrates that the age of the seedling and its genotypic makeup are important factors for obtaining high-frequency adventitious shoot regeneration from cotyledons of tetraploid watermelon. In general, the most organogenic explants were those obtained from 2-to 4-day-old in vitro-germinated seedlings. However, the optimal age may vary 1 to 2 days for each genotype. This finding differs from that of protocols for diploid watermelon, which suggested that cotyledons from 5- to 7-day-old seedlings be used (Compton and Gray, 1993; Dong and Jia, 1991; Srivastava et al., 1989).

The low fertility of tetraploid plants makes clonal propagation an attractive alternative to sexual reproduction as a means of increasing the number of superior tetraploid individuals to be used in seedless watermelon production. Some have proposed that axillary shoot proliferation from shoot-tip explants be used to propagate tetraploid parentals for triploid seed production (Compton and Gray, 1992; Compton et al., 1993; Gray and Elmstrom, 1988). However, our method of adventitious shoot regeneration from seedling cotyledons could also be used as a means of increasing the number of superior tetraploid individuals, provided that somaclonal variation is minimal. 


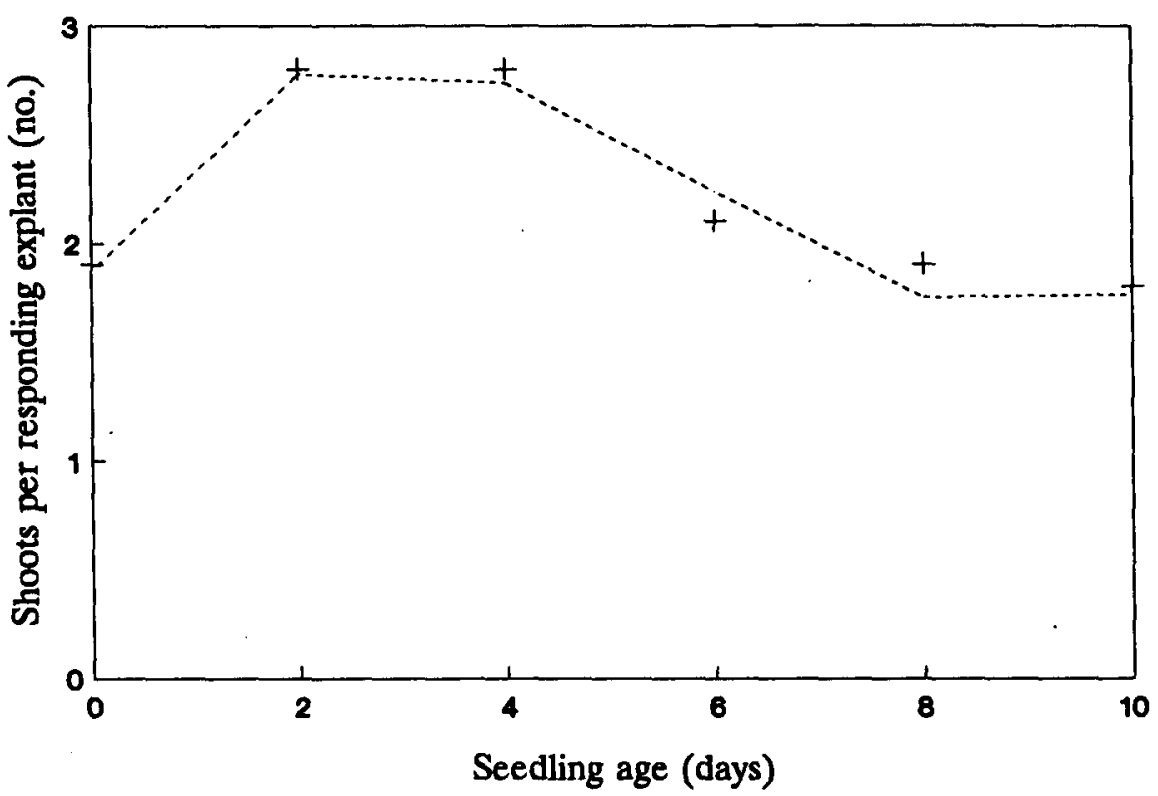

Fig. 2. Effect of seedling age on the number of shoots per responding explant. Explants were cotyledons from mature seed (0) or 2-, 4-, 6-, 8-, or 10-day-old seedlings from four tetraploid watermelon breeding lines (F92U8, SP90-1, SP90-2, and SP90-4). For protocols, see text. The number of responding explants per treatment ranged from 45 to 198 . Dotted line represents the predicted regression equation: $\mathrm{Y}=1.872+$ $0.769 x-0.178 x^{2}+0.01 x^{3}$

\section{Literature Cited}

Anghel, L and A. Rosu. 1985. In vitro morphogenesis in diploid, triploid and tetraploid genotypes of watermelon- Citrullus lanatus (Thunb.)
Proc. Fla. State Hort. Soc. 105:352-354.

Compton, M.E. and D.J. Gray. 1993. Shoot organogenesis and plant regeneration from cotyledons of diploid, triploid, and tetraploid watermelon. J. Amer. Soc. Hort. Sci. 118:151-157.

Compton, M.E., D.J. Gray, and G.W. Elmstrom. 1993. A simple protocol for micropropagating diploid and tetraploid watermelon using shoot-tip explants. Plant Cell Tissue Organ Cult. 33:211217.

Dong, J.-Z. and S.-R. Jia. 1991. High efficiency plant regeneration from cotyledons of watermelon (Citrullus vulgaris Schrad.). Plant Cell Rpt. 9:559-562.

Gray, D.J. and G.W. Elmstrom. 1988. Novel process for the accelerated production of triploid seeds for seedless watermelon cultivars. U.S. Patent 5,007,198.

Kleinbaum, D.G. and L.L. Kupper. 1978. Applied regression analysis and other multivariable methods. PWS Publishers, Boston.

Lentner, M. and T. Bishop." "1986. Experimental design and analysis. Valley Book Co., Blacksburg, Va.

Murashige, T. and F. Skoog. 1962. A revised medium for rapid growth and bioassays with tobacco- tissue cultures. Physiol. Plant. 15:473497.

SAS Institute, Inc. SAS/STAT user's guide. 1988. Release 6.03. SAS Inst., Cary, N.C.

Srivastava, D.R., V.M. Andrianov, and E.S Piruzian. 1989. Tissue culture and plant regeneration of watermelon (Citrullus vulgaris Schrad. Cv. Melitopolski). Plant Cell Rpt. 8:300-302

$$
55 \text {. }
$$

Compton, M.E. and D.J. Gray. 1992. Micropropagation as a means of rapidly propagating triploid and tetraploid watermelon.
Zar, J.H. 1984. Biostatistical analysis. 2nd ed. Prentice Hall, Englewood Cliffs, N.J. 